\title{
Characterization of Space Environmental Effects on Candidate Solar Sail Material
}

\author{
David Edwards $^{\mathrm{a}}$, Whitney Hubbs ${ }^{\mathrm{a}}$, Tesia Stanaland ${ }^{\mathrm{b}}$, Andrew Hollerman ${ }^{\mathrm{b}}$, Richard Altstatt ${ }^{\mathrm{c}}$ \\ ${ }^{a}$ National Aeronautics and Space Administration, Marshall Space Flight Center \\ Mail Stop ED31, MSFC, Alabama, USA 35812 \\ ${ }^{\mathrm{b}}$ University of Louisiana at Lafayette, Department of Physics \\ P. O. Box 44210, Lafayette, Louisiana, USA 70504-4210 \\ ${ }^{\mathrm{c}}$ National Aeronautics and Space Administration, Marshall Space Flight Center \\ Mail Stop ED44, MSFC, Alabama, USA 35812
}

\begin{abstract}
The National Aeronautics and Space Administration's (NASA) Marshall Space Flight Center (MSFC) is concentrating research into the utilization of photonic materials for spacecraft propulsion. Spacecraft propulsion, using photonic materials, will be achieved using a solar sail. A sail operates on the principle that photons, originating from the sun, impart pressure and provide a source of spacecraft propulsion. The pressure can be increased, by a factor of two if the sun-facing surface is perfectly reflective. Solar sails are generally composed of a highly reflective metallic front layer, a thin polymeric substrate, and occasionally a highly emissive back surface. The Space Environmental Effects Team at MSFC is actively characterizing candidate solar sail materials to evaluate the thermo-optical and mechanical properties after exposure to a simulated Geosynchronous Transfer Orbit (GTO) radiation environment. This study is the first known characterization of solar sail materials exposed to space simulated environments. The technique of radiation dose verses material depth profiling was used to determine the orbital equivalent exposure doses. The solar sail exposure procedures and results of the material characterization will be discussed.
\end{abstract}

Keywords: solar sail, space environmental effects, radiation, material, ultralight weight.

\section{INTRODUCTION}

A solar sail is a thin membrane material that uses the momentum, carried by photons, to propel spacecraft. These photons originate from the sun, or can be beamed onto the sail with a laser. If the sail is a perfect reflector, then the momentum transferred to the sail can be almost doubled. Since the momentum carried by a single photon is extremely small, the surface area of a solar sail must be large to produce a reasonable acceleration. In addition to the large surface area, the sail must be lightweight, as indicated by

$$
\mathrm{a}_{0}=2 \mathrm{AP} / \mathrm{m} \text {. }
$$

where $\mathrm{a}_{0}$ is the characteristic acceleration of the solar sail, $\mathrm{A}$ is the surface area, $\mathrm{P}$ is the incident radiation pressure, and $\mathrm{m}$ is the mass. ${ }^{1}$ The challenge of developing a material that is both lightweight and reflective is further complicated by the requirement that the material must survive in the space environment. 
This paper will describe the testing and characterization of four candidate materials subjected to a simulated Geosynchronous Transfer Orbit (GTO) radiation environment. The four materials were aluminized Mylar ${ }^{\mathrm{TM}} 2$, aluminized Mylar with a chromium back surface, aluminized Colorless Polyamide $1\left(\mathrm{LaRC}^{\mathrm{TM}}-\mathrm{CP} 1\right)^{3}$ and aluminized Kapton $^{\mathrm{TM}} 2$. Each material was scheduled to receive a simulated radiation dose equivalent to 1, 2, 4, and 6 months in a GTO environment. After each incremental exposure, the materials were characterized, evaluating the thermo-optical properties of solar absorptance $\left(\alpha_{\mathrm{s}}\right)$ and infrared emittance $(\varepsilon)$. The mechanical property of stress at maximum load was also measured.

The materials were exposed to a radiation dose equivalent that the solar sails would receive during GTO. This radiation environment definition was obtained using the AE8 model $^{4}$. It was used to generate the radiation dose verses material thickness, or dose-depth profile.

\section{PHYSICS OF SOLAR SAILS}

Solar sailing has become an increasingly attractive propulsion system for long term missions where the cost of chemically propelled vehicles would be prohibitive. Solar sails would allow applications such as station keeping in areas that cannot be occupied by conventionally propelled satellites due to excessive fuel requirements. Solar sail powered missions are capable of achieving non-Keplerian orbits ${ }^{1}$ and can provide high velocities for long duration missions. Conventional propulsion techniques require the acceleration of mass expelled from the spacecraft to produce thrust. This mass is finite and will limit the available velocity change of the spacecraft. Solar sails require virtually no fuel mass, which makes it an attractive propulsion system for in-space propulsion.

Solar sails are analogous to atmospheric wind sailing of historic reference. The modern space version operates using photon pressure. These photons interact with the sail and impart momentum. Because the momentum of an individual photon is extremely small, a large number of photons needs to be intercepted. To do this, solar sails must have a large surface area. In addition, to generate a large acceleration, solar sails must be lightweight, as shown in equation 1. Solar sails are generally designed to be highly reflective so the sail receives an additional momentum from the photon reflection. Gray, et $\mathrm{al}^{5}$ have experimentally measured the photon force and found the relationship between the total force on the sail and the material reflectivity to be

$$
\mathrm{F}=(1+\mathrm{R})\left(4.56 \times 10^{-6} \mathrm{~N} / \mathrm{m}^{2}\right)(\mathrm{A})(\mathrm{I}) .
$$

where $\mathrm{F}$ is the force experienced by the sail, $\mathrm{R}$ is the reflectivity of the material, $\mathrm{A}$ is the surface area, and $\mathrm{I}$ is the photon intensity of the sun at one Astronomical Unit (AU) at Air Mass Zero (AM0).

In the derivation of equation 2 , it is noted that the momentum for a moving object was defined as

$$
\mathrm{p}=\mathrm{Ft} \text {. }
$$

where $\mathrm{p}$ is the momentum and $\mathrm{F}$ is the force applied over time $\mathrm{t}$. Recalling that the momentum can also be defined as

$$
\mathrm{p}=\mathrm{E} / \mathrm{c} \text {. }
$$

where $\mathrm{E}$ is the energy of a photon and $\mathrm{c}$ is the speed of light in a vacuum. Then substitute equation 4 into equation 3 to get

$$
\mathrm{F}=\mathrm{E} / \mathrm{ct}
$$

The pressure, $\mathrm{P}$ can be defined as the force, $\mathrm{F}$, divided by the area, $\mathrm{A}$, so we get

$$
\mathrm{P}=\mathrm{F} / \mathrm{A}=\mathrm{E} / \mathrm{Act} .
$$


This defines the photon energy flux, I, as the energy per unit area per unit time and substitutes this relationship into equation 6 to get

$$
\mathrm{P}=\mathrm{I} / \mathrm{c} .
$$

Intensity at $1 \mathrm{AU}$ and $\mathrm{AM} 0$ is defined as $1368 \mathrm{~W} / \mathrm{m}^{2}$ and the speed of light in a vacuum is $3 \times 10^{8} \mathrm{~m} / \mathrm{s}$. Using these definitions, the photon pressure at $1 \mathrm{AU}$ was calculated, on a perfectly absorbing sail, to be

$$
\mathrm{P}=4.56 \times 10^{-6} \mathrm{~N} / \mathrm{m}^{2} .
$$

Since the sail also gains momentum from the photon reflection, Gray et al. include this variable as

$$
P=(1+R)\left(4.56 \times 10^{-6} \mathrm{~N} / \mathrm{m}^{2}\right) .
$$

Using the relationship defined by equation 6 and substituting into equation 9, we get the general form of the theoretical maximum force as shown in equation 2 .

\section{DESCRIPTION OF THE FACILITY}

The Environmental Effects Group at Marshall Space Flight Center (MSFC) operates the Low Energy Electron (LEE) test system. This system provides the capability to irradiate material to a simultaneous or sequential exposure to a simulated space environment. The low energy electrons originate from a Kimball Physics model EFG-9 electron gun. The energy range of the electrons was selectable from 1 to $50 \mathrm{keV}$. Electron flux was also selectable and ranged from 1 to 500 $\mathrm{nA} / \mathrm{cm}^{2}$ at the higher energy limit. The electron flux used in this investigation was $2 \mathrm{nA} / \mathrm{cm}^{2}$. Two Faraday cups monitor the flux produced by the flood gun. An in-line Faraday cup is located between the flood gun and the test chamber and is remotely controlled to cycle, vertically, into and out of the electron beam path. Another Faraday cup is located in the test chamber and constantly monitors the electron beam current at the sample position. Figure 1 shows the LEE test system at MSFC.

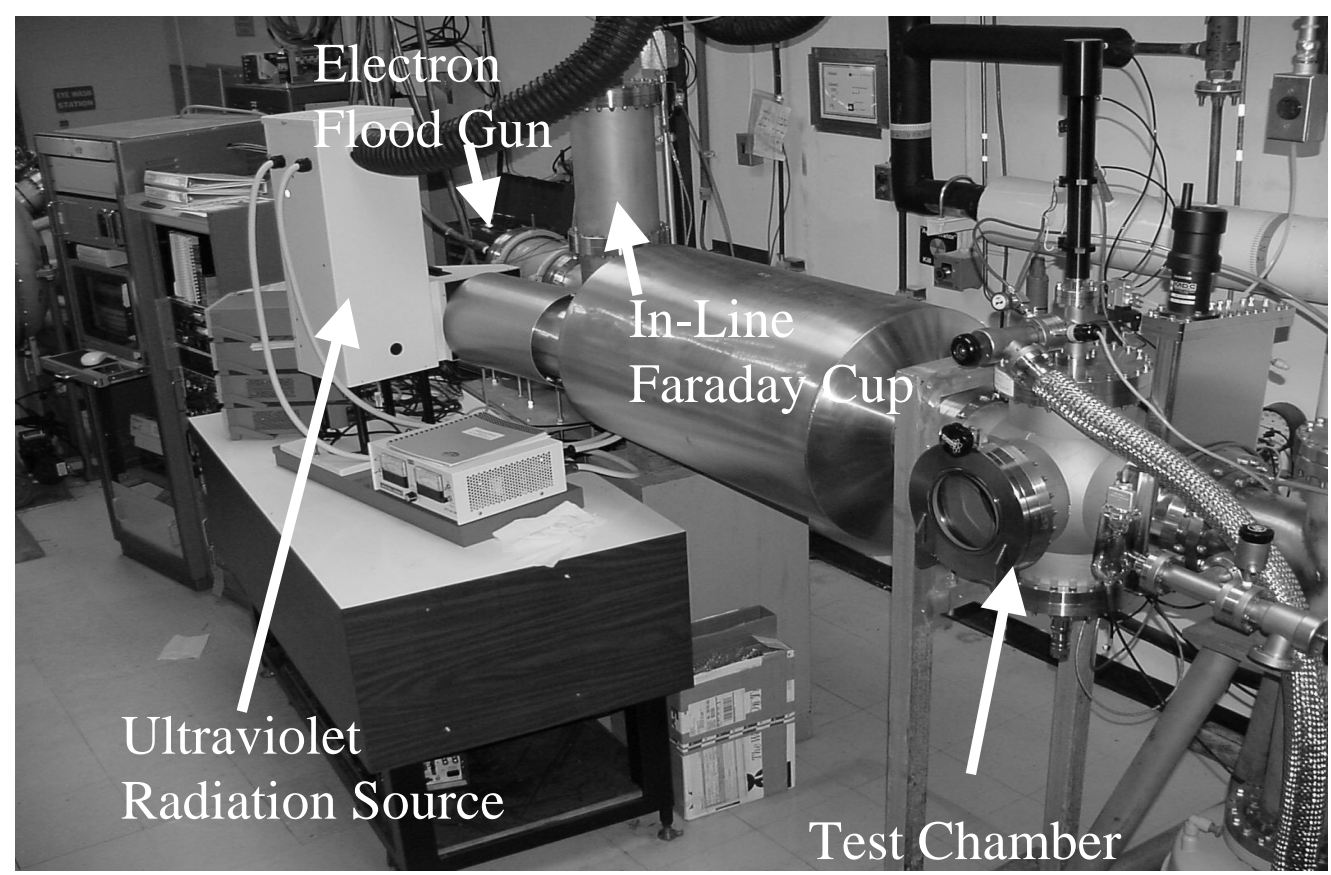

Figure 1. Low Energy Electron (LEE) System at MSFC. 
The LEE test system also offers the capability of illuminating test samples to Near Ultraviolet (NUV) radiation. The NUV is produced by an Oriel enhanced ultraviolet radiation source. The photon intensity is selectable and ranges from less than 1 thermal sun $\left(1358 \mathrm{~W} / \mathrm{m}^{2}\right)$ to greater than 10 thermal suns $\left(13,580 \mathrm{~W} / \mathrm{m}^{2}\right)$. The NUV source was not utilized in this test.

\section{MATERIAL DESCRIPTION}

The aluminized Mylar was nominally 3 microns thick with $50 \mathrm{~nm}$ of aluminum deposited on each surface. This material also utilized Kevlar ${ }^{\mathrm{TM}} 2$ threads, on one surface, to serve as a rip-stop mechanism. The Kevlar threads were positioned on 1-inch centers. Tensile strips of this material were cut from between the Kevlar threads.

The aluminized Mylar with back surface chromium has a Mylar thickness of 0.9 microns. The front, or sun facing, side was deposited with $50 \mathrm{~nm}$ of aluminum. The back, or anti-sun facing side, was deposited with $20 \mathrm{~nm}$ of chromium. The chromium has a higher emissivity than aluminum and radiates heat more efficiently.

The aluminized CP1 was 3 microns thick with $50 \mathrm{~nm}$ of aluminum deposited on the sun facing surface. CP1 is colorless, moisture resistant, and a low dielectric. It also has long-term storage capabilities.

The aluminized Kapton was 8 microns thick with $50 \mathrm{~nm}$ of aluminum deposited on the sun facing side. Kapton maintains properties at extreme temperatures. These properties include antistatic, thermally conductive, corona resistant, pigmented for color, and conformable.

Each material was cut into tensile strips $20.3 \mathrm{~cm}$ ( 8 in) long and $2.0 \mathrm{~cm}(0.75 \mathrm{in})$ wide. With exception of the thicker aluminized Kapton, cutting the material tensile strips resulted in some degree of tearing around the edges.

\begin{tabular}{|c|c|c|}
\hline Material & $\begin{array}{c}\text { Thickness } \\
\text { (microns) }\end{array}$ & $\begin{array}{c}\text { Deposited Aluminum } \\
\text { (nm) }\end{array}$ \\
\hline Aluminized Mylar & 3.0 & 50 \\
\hline $\begin{array}{c}\text { Aluminized Mylar with } \\
\text { chromium backing }\end{array}$ & 0.9 & 50 \\
\hline Aluminized Kapton & 8.0 & 50 \\
\hline CP1 & 3.0 & 50 \\
\hline
\end{tabular}

Table 1. Characteristics of materials

\section{EXPERIMENTAL PROCEDURE}

\subsection{Material preparation}

Candidate materials were obtained from various sources for this investigation. The materials were prepared for this test by cutting the material into tensile strips. The material was placed on a vacuum cutting table to reduce wrinkling in the material and, thus, allow for increased accuracy in cutting tensile strips. After the tensile strips were prepared, the samples were marked for identification and the optical properties measured prior to exposure. Several samples were used to determine the Beginning of Life (BOL) mechanical properties. Once the baseline optical and mechanical properties were obtained, the samples were placed in the sample holder and loaded into the test chamber. These samples were then exposed to a 1 month equivalent GTO exposure. After the exposure, the samples were removed, optical property measurements were obtained, and then mechanical properties evaluated. This procedure was repeated for the 2, 4, and 6 months equivalent exposures. New sets of samples were used for each exposure sequence. 


\subsection{Dose-depth profile}

The natural space electron environment for a GTO is a continuum of energies from less than a $\mathrm{keV}$ to hundreds of $\mathrm{GeV}$. Since it is not possible to simulate the whole electron spectrum at once, the process for determining effects was to reproduce the does-depth profile in a material. The target electron environment used in this investigation was based on a one year GTO exposure. The error bars in figure 2 show the variability of the GTO electron environment. Since this investigation was consisted of several various materials, a single material was selected to serve as a representative, or standard material. The material chosen was Mylar. The GTO electron dose deposited in the Mylar film was determined using the software code Space Radiation. The Integrated Tiger Series 3 (ITS3) code was used to determine the dose-depth profile for three mono-energetic electron beams. The results of this analysis are shown in figure 2. Individual contributions from the three energies are summed to generate the curve labeled "Total Electrons" in figure 2. Notice that the "Total Electron" curve is reasonably similar to the GTO data, and well within the variability of the environment.

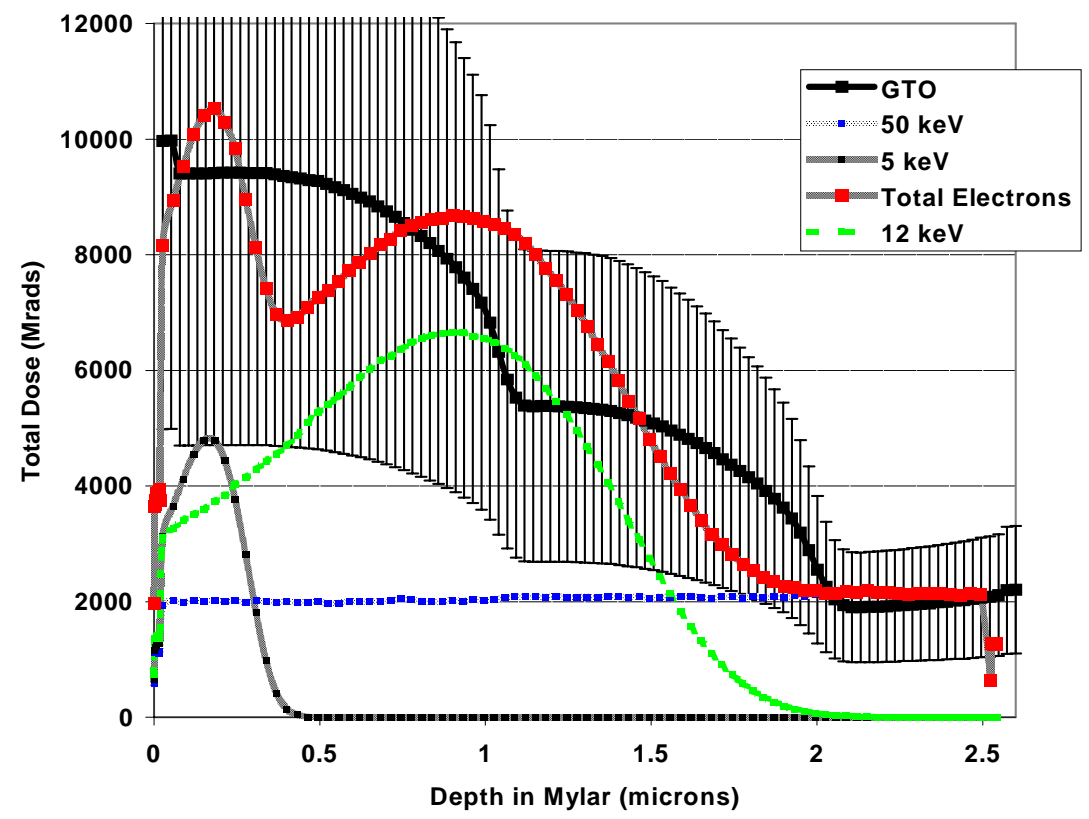

Figure 2. Dose-Depth profile for Mylar in GTO for 1 year.

\subsection{Electron Exposure}

The dose-depth profile for various times in a GTO can be simulated using a linear combination of 5,12 , and $50 \mathrm{keV}$ electron beams as shown in tables 2 to 5 . Individual exposure times for each beam were adjusted to match the dosedepth profile to the GTO electron environment. Sail samples were irradiated using a Kimball Physics EFG-9 electron gun. The electron beam energy and current can be adjusted from 1 to $50 \mathrm{keV}$ and $10^{-9}$ to $10^{-4} \mathrm{~A}$ respectively.

\begin{tabular}{|c|c|c|c|}
\hline $\begin{array}{l}\text { Electron Energy } \\
(\mathrm{keV})\end{array}$ & $\begin{array}{l}\text { Average Flux } \\
\left(\mathrm{nA} / \mathrm{cm}^{2}\right)\end{array}$ & $\begin{array}{c}\text { Exposure Time } \\
\text { (hours) }\end{array}$ & $\begin{array}{c}\text { Calculated Fluence } \\
\left(\text { electrons } / \mathrm{cm}^{2}\right)\end{array}$ \\
\hline 50 & 2 & 23.77 & $1.08 \mathrm{E} 15$ \\
\hline 12 & 2 & 10.98 & $5.00 \mathrm{E} 14$ \\
\hline 5 & 2 & 4.21 & $1.92 \mathrm{E} 14$ \\
\hline
\end{tabular}

Table 2. Electron exposure parameters for a 1 month equivalent GTO exposure 


\begin{tabular}{|c|c|c|c|}
\hline $\begin{array}{c}\text { Electron Energy } \\
(\mathbf{k e V})\end{array}$ & $\begin{array}{c}\text { Average Flux } \\
\left(\mathbf{n A} / \mathbf{c m}^{\mathbf{2}}\right)\end{array}$ & $\begin{array}{c}\text { Exposure Time } \\
(\text { hours })\end{array}$ & $\begin{array}{c}\text { Calculated Fluence } \\
\left(\mathbf{e l e c t r o n s} / \mathbf{c m}^{\mathbf{2}}\right)\end{array}$ \\
\hline 50 & 2 & 47.55 & $2.17 \mathrm{E} 15$ \\
\hline 12 & 2 & 21.95 & $1.00 \mathrm{E} 15$ \\
\hline 5 & 2 & 8.41 & $3.83 \mathrm{E} 14$ \\
\hline
\end{tabular}

Table 3. Electron exposure parameters for a 2 month equivalent GTO exposure

\begin{tabular}{|c|c|c|c|}
\hline $\begin{array}{c}\text { Electron Energy } \\
(\mathbf{k e V})\end{array}$ & $\begin{array}{c}\text { Average Flux } \\
\left(\mathbf{n A} / \mathbf{~ c m}^{\mathbf{2}}\right)\end{array}$ & $\begin{array}{c}\text { Exposure Time } \\
(\text { hours })\end{array}$ & $\begin{array}{c}\text { Calculated Fluence } \\
\left(\mathbf{e l e c t r o n s} / \mathbf{c m}^{\mathbf{2}}\right)\end{array}$ \\
\hline 50 & 2 & 95.10 & $4.33 \mathrm{E} 15$ \\
\hline 12 & 2 & 43.89 & $2.00 \mathrm{E} 15$ \\
\hline 5 & 2 & 16.2 & $7.67 \mathrm{E} 14$ \\
\hline
\end{tabular}

Table 4. Electron exposure parameters for a 4 month equivalent GTO exposure

\begin{tabular}{|c|c|c|c|}
\hline $\begin{array}{c}\text { Electron Energy } \\
(\mathbf{k e V})\end{array}$ & $\begin{array}{c}\text { Average Flux } \\
\left(\mathbf{n A} / \mathbf{c m}^{\mathbf{2}}\right)\end{array}$ & $\begin{array}{c}\text { Exposure Time } \\
(\mathbf{h o u r s})\end{array}$ & $\begin{array}{c}\text { Calculated Fluence } \\
\left(\mathbf{e l e c t r o n s} / \mathbf{c m}^{\mathbf{2}}\right)\end{array}$ \\
\hline 50 & 2 & 142.64 & $6.50 \mathrm{E} 15$ \\
\hline 12 & 2 & 65.83 & $3.00 \mathrm{E} 15$ \\
\hline 5 & 2 & 25.24 & $1.15 \mathrm{E} 15$ \\
\hline
\end{tabular}

Table 5. Electron exposure parameters for a 6 month equivalent GTO exposure

\section{RESULTS}

Four candidate solar sail materials were exposed to electron radiation doses equivalent to a GTO. The materials were characterized after each exposure. Characterization properties consisted of thermo-optical measurements (solar absorptance and emittance) and mechanical properties (stress at maximum load). The original test plan indicated the materials would be exposed to radiation doses equivalent to 1,2, and 6 months in GTO. In reality, only one material, aluminized Kapton, was exposed to the full 6 months equivalent exposure and then characterized to determine the radiation effects on the mechanical properties. The remaining materials were damaged after 1 or 2 months equivalent exposure and their mechanical properties could not be determined. Preparation of the tensile specimens resulted in numerous rips or tears in the gauge length on the material. As a result, the absolute validity of the tensile measurements is questionable. The mechanical property data obtained from this investigation is shown in figure 3.

Thermo-optical property measurements were obtained for the candidate sail materials. Figure 4 shows the solar absorptance as a function of exposure duration at GTO. The measurement error for solar absorptance is $\pm 0.03^{7}$. The data in figure 4 shows that none of the tested materials show changes in absorptance that are larger than the measurement error. Figure 5 shows the emittance as a function of exposure duration at GTO. Measurement error for emittance is $\pm 0.01^{8}$. The data displayed in figure 5 indicates that electron exposure does not appear to affect the emittance for three of the tested materials. Emittance for the chromium-backed aluminized Mylar sample appears to increase with GTO exposure. Additional measurements will be completed to further quantify these results. 


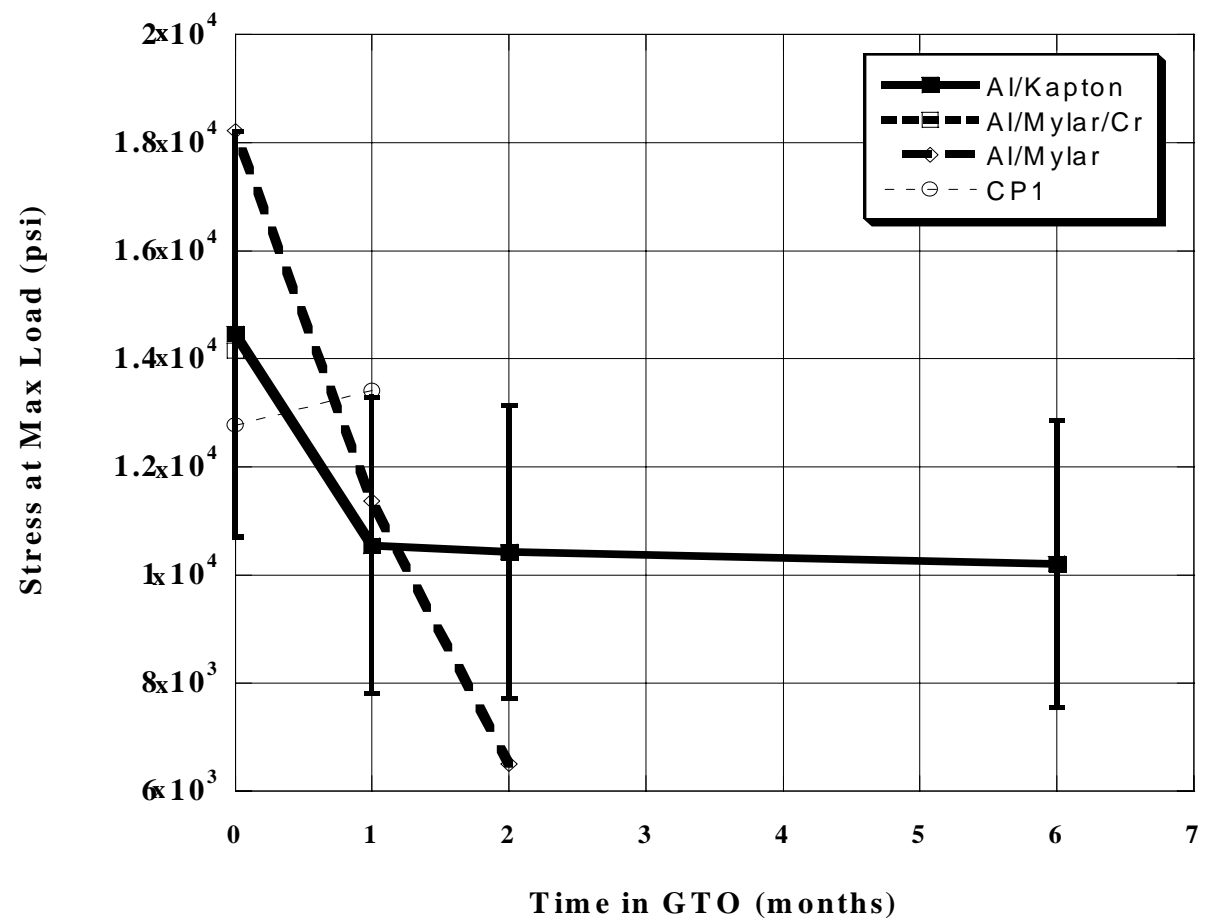

Figure 3. Effects of a simulated GTO dose on the stress of candidate solar sail material

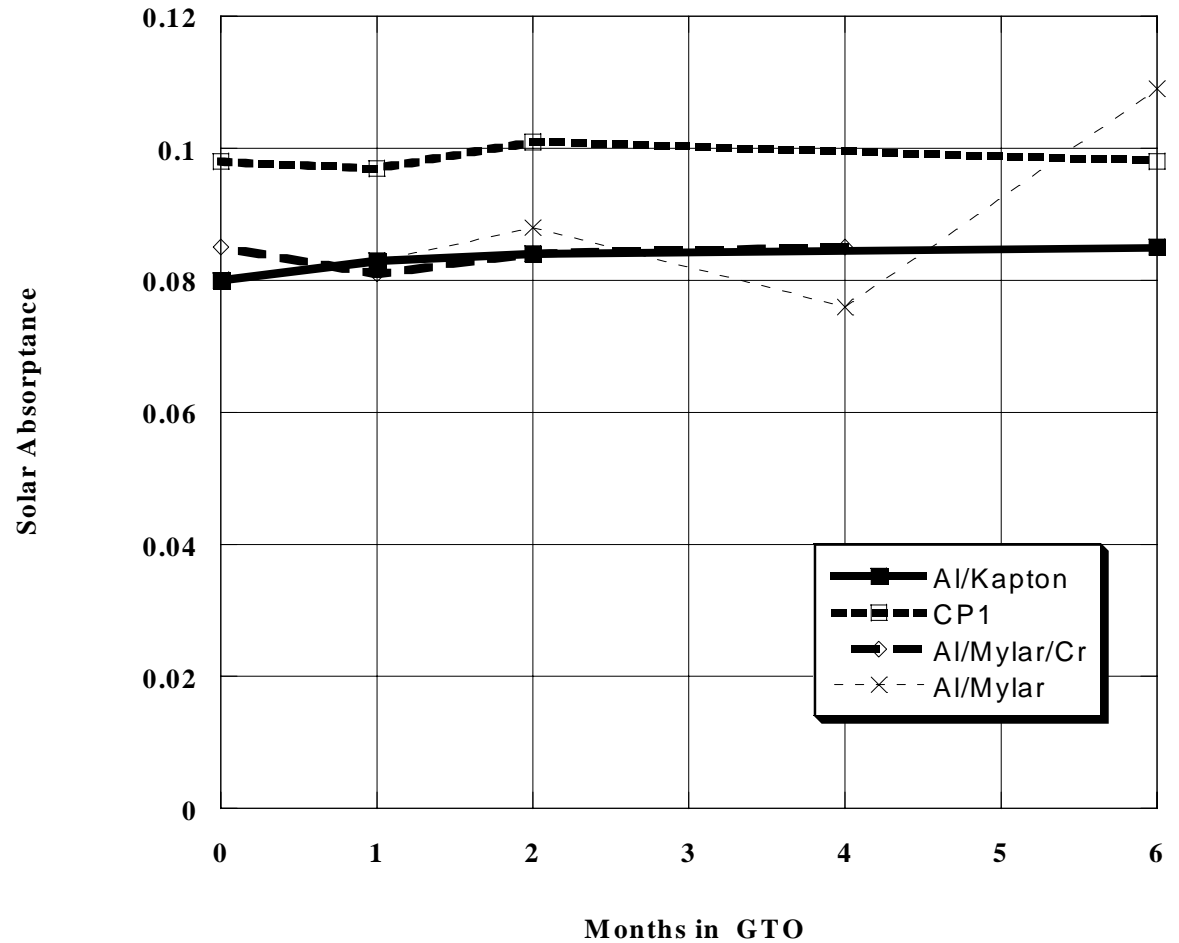

Figure 4. Solar absorptance of the candidate sail materials after exposure to equivalent GTO exposure 


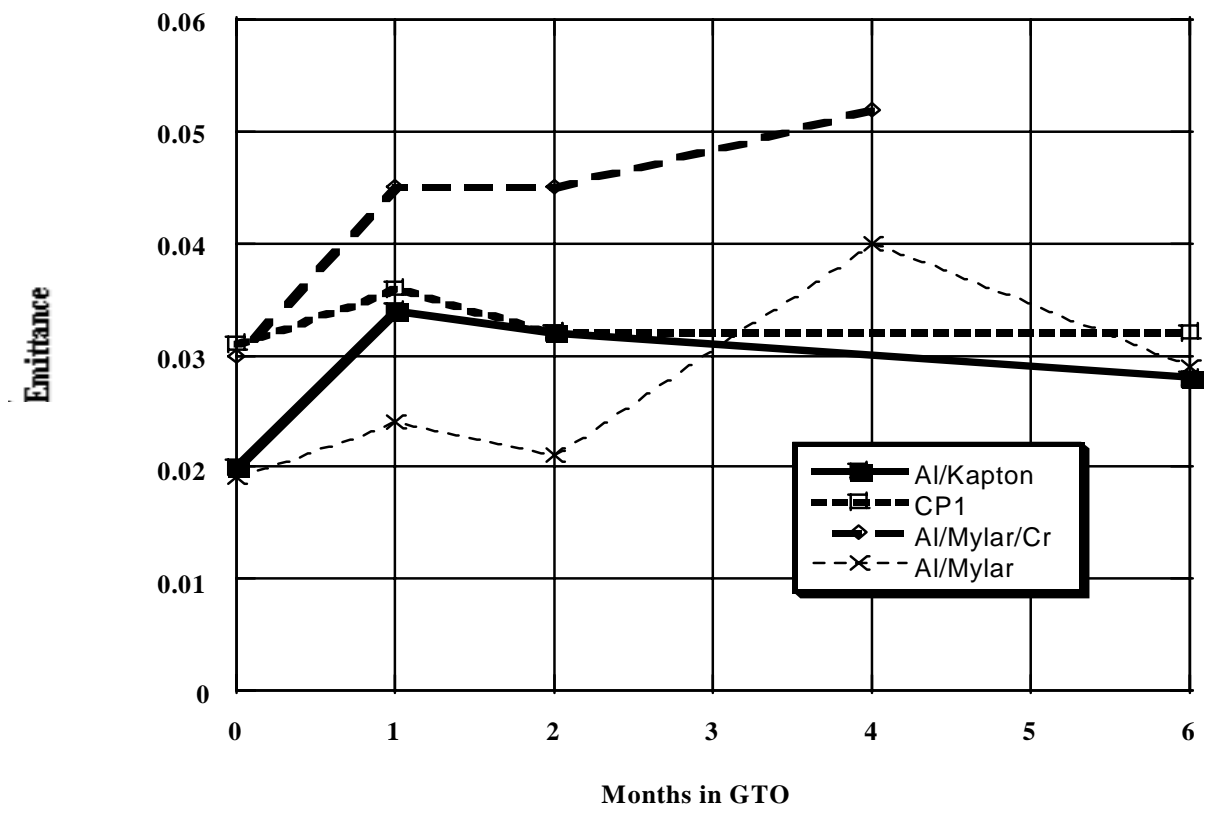

Figure 5. Emittance of the candidate sail materials after exposure to equivalent GTO exposure

\section{CONCLUSIONS}

This is the first known space environmental effects test on these candidate solar sail materials. The initial results are inconclusive regarding the exact behavior of sail materials in the space environment. Qualitatively, the authors observed significant degradation of mechanical properties after radiation exposure. The data reinforces the fact that the thermo-optical properties do not significantly degrade. From this preliminary data, it appears the space environment will not significantly affect the propulsion performance of the sail. Additional measurements are being completed to further quantify the performance of these materials.

\section{REFERENCES}

1. C.R. McInnes, Solar Sailing: Technology, Dynamics and Mission Applications, p.14, Praxis Publishing, Chichester, UK, 1999

2. Registered trademark of E. I. duPont de Nemours and Company

3. Registered trademark of SRS Technologies

4. J.I. Vette, AE/AP Trapped Particle Flux Maps 1966-1980 web document

5. P.A. Gray, D.L. Edwards, M.R. Carruth, Preliminary Photon Pressure Measurements Using a Solar Simulator, AIAA 2001-1136, Reno, Nevada, January, 2001.

6. ITS3, Radiation Shielding Information Center, Oak Ridge National Laboratory, CCC-467, 1992

7. A Z Technology: Laboratory Portable Spectroreflectometer Model LPSR-200, 1993

8. A Z Technology: Total Emittance Measurement Portable (TEMP), 1995 